\title{
Apresentação metodológica com uso de tecnologia digital no ensino de ciências
}

\author{
Liliane Silva Câmara de Oliveira \\ Mestranda em Ensino de Ciências e Educação Matemática \\ Universidade Estadual da Paraíba - UEPB/PPGECEM \\ 凹lilianecamara2007@gmail.com \\ Dennefe Vecencia Bendito \\ Mestranda em Ensino de Ciências e Educação Matemática \\ Universidade Estadual da Paraíba - UEPB/PPGECEM \\ Nívia Maria Rodrigues dos Santos \\ Mestranda em Ensino de Ciências e Educação Matemática \\ Universidade Estadual da Paraíba - UEPB/PPGECEM \\ Karla Patrícia de Oliveira Luna \\ Prof ${ }^{a}$ Doutora do Departamento de Biologia \\ Universidade Estadual da Paraíba - UEPB, Campina Grande/PB \\ \karlaceatox@yahoo.com.br
}

Aceito em 13 de julho de 2017

\section{Resumo:}

A introdução em sala de tecnologias digitais vem se mostrando eficiente para o aprendizado do aluno, pois sua utilização permite uma vivencia educacional em tempo integral. Os alunos que nasceram na era digital, além de não terem dificuldade com aparelhos, acham esses meios atrativos para seu aprendizado. Este estudo apresenta uma experiência com uso da rede social educacional Edmodo no ensino de ciências. O objetivo é apresentar situações de ensino mediadas por propostas motivacionais e veiculadas pela tecnologia digital, como também analisar as considerações dos mestrandos sobre o uso do Edmodo como ferramenta educacional apresentada para o ensino de ciências. Este trabalho é um relato de experiência sobre a utilização de ferramentas que possibilitem o aprendizado dos alunos em ensino de ciência com uso de TICs, realizado em laboratório de informática na Universidade Estadual da Paraíba - UEPB, com alunos do mestrado em Ensino de Ciências e Educação Matemática da mesma instituição. Foi proposto aos alunos do mestrado a utilização do Edmodo como ferramenta para o ensino de ciências, com algumas atividades inseridas na plataforma. Como resultado unânime, os mestrandos classificam como ótimo a utilização do espaço no Edmodo como possibilidade para o aprendizado em ensino de ciência mediante o uso de TICs. O uso da plataforma Edmodo provou ser uma excelente estratégia para professores trabalharem com seus alunos, pois, além de ter uma característica de rede social, possibilita uma maior troca de informações e pode ser acessada em dispositivos móveis de forma descomplicada.

Palavras-chave: Ensino de Ciências; Tecnologia Digital; Edmodo.

\section{Methodology presentation with use of digital technology in science teaching}

\section{Abstract:}

The introduction in room of the digital technologies has proven effective for student learning, because its use allows an educational experience in full time. Students who were born in the digital 
age, besides not having difficulty with appliances, find these attractive means for their learning. This study presents an experience with use of educational social network Edmodo in science education. It aims to present teaching situations mediated by motivational proposals and conveyed by digital technology, as also examine the considerations of master's about using Edmodo as an educational tool presented to the science education. This work is an experience report about the use of tools that enable students to learn in science teaching using TICs, carried out in a computer lab at the Paraíba State University - UEPB, with students of the masters in Science Teaching and Mathematics Education of the same institution. It was proposed to students of the masters degree the use of Edmodo as a tool for teaching science, with some activities included in the platform. As a unanimous result, the masters classify as great the use of space in Edmodo and the proposed activities through a survey. The use of the Edmodo platform proved to be an excellent strategy for teachers to work with their students, because, in addition to having a social networking feature, enables a greater exchange of information and can be accessed on mobile devices in an uncomplicated way.

Keywords: Science Teaching; Digital Technology; Edmodo.

\section{Metodología presentación digital con uso de la tecnología en la enseñanza de las ciencias}

\section{Resumen:}

La introducción em classes de tecnologias digitales se muestra una realidad educacional eficiente para el aprendizaje, uma vez que su uso permite una experiencia educacional em tiempo integral. Los alumnos que nasceran en la era digital, además de no teneren dificultad com los aparatos electrónicos, creen que estos medios son atraentes para su aprendizaje. Este estudio presenta uma experiencia con el uso de la red social educativo Edmodo, en la enseñanza de ciências. El objectivo del estúdio es presentar situaciones de enseñanza mediadas por propuestas motivacionales y unificadas por las tecnologias digitales, y tambien, analisar las consideraciones de los alumnos de maestría sobre el uso del Edmodo como herramienta educacional para la enseñanza de las ciéncias. Este trabajo es un relato de experiencia sobre la utilización de herramientas que posibiliten el aprendizaje de los alumnos en enseñanza de ciencia con uso de TICs, realizado en laboratorio de informática en la Universidad Estadual de Paraíba - UEPB, con alumnos del máster en Enseñanza de Ciencias y Educación Matemáticas de la misma institución. Se propuso a los alumnos de la maestría la utilización del Edmodo como herramienta para la enseñanza de las ciencias, con algunas actividades insertadas en la plataforma. Como resultado unánime, los estudiantes de maestría se clasifican como un buen uso del espacio en Edmodo y las actividades propuestas a través de una encuesta. El uso de la plataforma Edmodo ha demostrado ser una excelente estrategia para que los maestros trabajan con los estudiantes, ya que, además de una función de red social, permite un mayor intercambio de información y se puede acceder en dispositivos móviles sin complicaciones.

Palabras clave: Enseñanza de las Ciéncias; Tecnología Digital; Edmodo.

\section{INTRODUÇÃO}

O momento de aula deve ser muito proveitoso, pois ele pode propiciar uma troca de informações relevantes para o crescimento profissional e pessoal dos indivíduos ali presentes. "O professor aprende ao ensinar e o aluno ensina ao aprender" (FREIRE, 2009 p. 23). É uma construção de conhecimentos científicos que repercutem no crescimento do 
cidadão, pois possibilita um amadurecimento no comportamento e traz mudanças sociais e cientificas de acordo com o contexto sociocultural.

A introdução em sala de tecnologias digitais vem se mostrando eficiente para o aprendizado do aluno, pois sua utilização permite uma vivencia educacional em tempo integral. O fator limitante para a utilização desta ferramenta nas escolas e fora delas é a acessibilidade aos meios eletrônicos e a internet que ainda é muito diferenciada na sociedade atual (SOUZA et al., 2011).

Os alunos que nasceram na era digital, além de não terem dificuldades com aparelhos como computadores, tabletes, smartphones e celulares, acham esses meios importantes para o aprendizado. Porém, o que ainda vemos na sociedade atual é que nem todos podem possuir um aparelho destes, nem tão pouco terem acesso à internet. As escolas também não estão equipadas de forma suficiente para atender esta necessidade social abrangendo a todos os seus alunos.

Aos professores que se encontram em situações que possibilitem o uso dessas tecnologias digitais existe a oportunidade de cadastrarem suas turmas em plataformas online onde podem organizar suas aulas, trabalhos, notas e ainda possibilitar a interação dos seus alunos com ele e entre eles, são as chamadas redes sociais educacionais.

Este estudo apresenta uma experiência com uso da rede social educacional Edmodo no ensino de ciências, avaliada por alunos do Programa de Mestrado em Ensino de Ciências e Educação Matemática - PPGCEM da Universidade Estadual da Paraíba - UEPB.

Teve por objetivo apresentar situações de ensino mediadas por propostas motivacionais e veiculadas pela tecnologia digital, como também analisar as considerações dos mestrandos sobre o uso da plataforma Edmodo como ferramenta educacional apresentada para o ensino de ciências.

\section{O ENSINO DE CIÊNCIAS: DESAFIOS E DEFORMAÇÕES}

Muitos professores têm se preocupado com o ensino realizado em sala de aula, e necessariamente, com o reflexo social que pode haver a partir das abordagens escolhidas no 
processo de ensino e aprendizagem, visto a necessidade de preparação dos alunos para a formação crítica. Em muitas dessas reflexões há grandes insatisfações e receios, pois reside um paradigma onde há por um lado os desafios enfrentados pelos professores no que diz respeito a sua formação e por outro as deformações sobre o ensino de ciências.

Quando se fala em desafios, um dos processos marcantes é a formação docente a qual espera-se que seja capaz de preparar os professores para a diversidade no ensino. Nesse ponto, ressaltam-se as considerações de Carvalho e Pérez (2006, p. 23-24) sobre as competências necessárias após a formação docente:

[...] Um professor precisa conhecer a história das Ciências; Conhecer quais foram as dificuldades, obstáculos epistemológicos; [...] Ter algum conhecimento dos desenvolvimentos científicos recentes e seus perspectivas.

Infelizmente, o que vem sendo percebido é que a formação deixa alguns espaços vazios. É nessa ausência de consciência que se encontra na educação escolar abordagens distorcidas e incoerentes com os modelos atualmente desejáveis, como por exemplo, as 'perspectivas interacionistas'.

Observa-se ainda uma recorrência aos modelos de períodos passados que refletem um pouco da insuficiência no ensino, visto que deixam limitações quanto as abordagens discursivas e dialógicas no processo de ensino e aprendizagem, entretanto, as mudanças e a busca por novas abordagens que atendam as demandas atuais caracteriza-se como uma busca permanente, isso desde os anos 60 até os dias atuais, mas só nos anos 80 é que percebemos mudanças mais significativas quanto as produções voltadas para o ensino de ciências.

Desde os anos 80 até hoje é grande a produção acadêmica de pesquisas voltadas à investigação das pré-concepções de crianças e adolescentes sobre os fenômenos naturais e suas relações com os conceitos científicos. Uma importante linha de pesquisa acerca dos conceitos intuitivos é aquela que, norteada por idéias piagetianas, se desenvolve acompanhada por estudos sobre História das Ciências, dentro e fora do Brasil (BRASIL, 1997, p.21).

O que acontece nos dias atuais, que apesar das dinâmicas diferenciadas e do contexto sociocultural modificado, não apresenta tanta diferença do ensino se comparado as décadas de 60,70 e 80 . Hoje é preciso perceber o aluno dentro de um contexto com diversas 
interferências, como é o caso das tecnologias e, dessa forma, os Parâmetros Curriculares Nacionais do Ensino de ciências alertam que:

\begin{abstract}
Numa sociedade em que se convive com a supervalorização do conhecimento científico e com a crescente intervenção da tecnologia no dia-a-dia, não é possível pensar na formação de um cidadão crítico à margem do saber científico. [...] A apropriação de seus conceitos e procedimentos pode contribuir para o questionamento do que se vê e ouve, para a ampliação das explicações acerca dos fenômenos da natureza. (BRASIL, 1997, p.21).
\end{abstract}

Nessa linha, é percebido atualmente a inserção de um novo pensar sobre o ensino de ciências que está distanciando cada vez mais a mentalidade de saber fixo e incontestável. Este pensamento vem abrindo espaço à contestação do que é ensinado e reflete nas consequentes mudanças no cenário atual. Tais consequências mostram-se por um lado de forma positiva, onde o aluno tem um papel de protagonista do seu aprendizado, e por outro os desafios para o professor, que a cada dia precisa melhorar sua prática.

Nesse espaço é importante analisar o ensino a fim de não levantar dúvidas da importância docente no processo, mesmo que se tenha formação caminhando com a necessidade de continuação. É preciso buscar sanar as desvalorizações, que em nada contribuem para a segurança no ensino, e tentar melhorar este quadro ao se colocar à disposição uma formação continuada de professores.

Para tanto, esta mudança paradigmática das práticas de ensino tende a propor práticas problematizadoras, que não ofereçam ao aluno apenas o conhecimento como algo inquestionável, mas que ele possa concomitante dialogar com os saberes prévios. Por esse motivo algumas mudanças são necessárias, como é o caso da superação do senso comum exemplificada por Delizoicov et al (2007, p. 32) como “[...] valorização excessiva pela repetição sistemática de definições e questões padrões para prontas respostas igualmente empobrecidas".

Olhando a supervalorização do senso comum, como uma prática também deformadora, abre-se espaço para pensar o que seriam essas deformações no ensino de Ciências segundo Pérez et al. (grifo do autor, 2001, p. 130-132), para isso, escolhemos três delas e nos deteremos a dialogar um pouco mais: 
[...] visão rígida (algorítmica, exata, infalível, ...); [...] visão aproblemática e ahistórica (portanto, dogmática e fechada); [...] visão acumulativa de crescimento linear socialmente neutra da ciência: esquecem-se as complexas relações entre ciência, tecnologia, sociedade (CTS) [...].

A visão rígida, seria aquela velha ideia de que a ciência é inquestionável, elaborada por cientistas e que não nos permitem repensar suas ideias, o que é muito estimulado nas salas de aula, sobretudo, quando são apresentadas visões únicas de um conteúdo, o que não permite a reflexão nem a problematização pelos alunos.

A visão a problemática, segundo Pérez et al. (2001), é a incapacidade de refletir sobre as temáticas, de não problematizar outras concepções que corroboraram e trouxeram controvérsias sobre o conteúdo estudado, oferecendo a ciência como pronta.

E, por fim, a visão acumulativa e neutra da ciência, como se ela fosse elaborada por certezas absolutas e longe do social. Essas visões abrem espaços para discursões e buscas de melhorias no processo de formação docente. É preciso sanar estes problemas, pois como vimos, a deformação na formação atinge diretamente o processo educativo como um todo.

\section{SITUAÇÕES DE APRENDIZAGEM}

Para pensar melhor sobre o ensino de ciências como uma realidade que pode ter melhores contribuições à formação crítica do aluno, torna-se conveniente falar de situações de ensino, necessariamente, pensando na motivação como um fator importante ao processo de ensino e aprendizagem. Nessa perspectiva, este texto está embasado principalmente nas ideias de Mizukami (1986) e Perrenoud (2000).

Segundo Mizukami (1986), a abordagem tradicional que trata de uma concepção resistente ao tempo e que se tornou de certa forma um referencial para outras abordagens que a ela seguiram, dessa forma, o tradicional permanece como pano de fundo de muitas práticas de ensino, pois como coloca a autora, as abordagens que a ela seguiram estiveram embasadas no tradicional, seja devido a insatisfação ou a insuficiência, o certo é que muitas situações de ensino e aprendizagem ainda estão espelhadas nesta forma. 
Não se pode negar que o ensino tem sido realizado com uma forte tendência ao tradicional, que por sua vez, não se vê representado apenas nos recursos que se utilizam em sala de aula, como o quadro e o pincel, mas pelas abordagens no que especifica Mizukami (1986). Para a autora as abordagens do processo irão direcionar o ensino a uma visão global ou a uma visão compartimentada, como se a ciência estivesse isolada das demais áreas e como se os conteúdos fossem expressões ditadoras de verdades absolutas, e não necessariamente os recursos que utilizamos.

Assim sendo, Mizukami (1986) apresenta algumas outras abordagens trazendo um pouco do percurso histórico, surgidas a partir do tradicionalismo. Entre elas, como forma de aproximação do que temos atualmente, encontra-se a abordagem sociocultural que prima por uma relação horizontal entre professor e aluno, a fim de que o processo educacional seja real.

Nessa abordagem, observa-se uma aproximação maior com as ideias atuais, onde a relação professor e aluno passa a acontecer de forma plural, ou seja, uma relação horizontal onde a aprendizagem não toma direção única, como na abordagem tradicional, o professor ensina e o aluno aprende.

Além dessas duas abordagens e como intenção de que o leitor pense as situações de ensino que se modificam a partir das abordagens utilizadas, é apresentada uma outra que diz respeito ao processo ensino-aprendizagem e ao professor. Segundo Mizukami (1986, p.99) ao citar que “[...] papel da teoria é, muitas vezes, limitado, [...]"e sua limitação deve servir também de guia para reflexão, levando assim o leitor ao foco de interesse, a tomada de reflexão sobre o processo de ensino e aprendizagem.

A autora, nessa abordagem, chama a atenção para a formação docente e complementa, que os cursos de formação precisam ser feito através do confronto de ideias e possibilidade de divergências (MIZUKAMI, 1986).

Pensando na contextualização traçada ao apresentar algumas das abordagens do processo de ensino e aprendizagem, apresentando o tradicionalismo muito criticado, até como forma de desmistificação de ideias a históricas sobre esse processo, faz-se necessário nesse momento discutir o ensino de ciências e o professor, voltando-se mais uma vez para a formação docente. 
É essencial entender que em um contexto de sala de aula, algumas abordagens precisam compor o cenário educacional, entre elas o uso do ensino tradicional se houver uma necessidade da aprendizagem mecânica. É importante pensar também em não desprezar o ensino quando se utiliza uma abordagem do tipo tradicional como sendo indevida e atrasada. Começando assim, a lançar novos e possíveis olhares ao ensino.

Nesse contexto, Perrenoud (2000, p. 25), divide o ensino em situações de aprendizagem que seguem: "[...] organizar e dirigir situações de aprendizagem é manter um espaço justo para tais procedimentos" e conclui que "ela consiste, de um lado, em relacionar os conteúdos e objetivos e, de outro, a situações de aprendizagens" (2000, p 26).

Assim, passa-se a considerar o ensino de ciências como uma organização para situações de aprendizagem que irão variar de acordo com a abordagem escolhida pelo professor. É por este motivo que mais uma vez voltamos a enfatizar a importância da formação docente, como forma de orientar e preparar os professores para as mais variadas situações de aprendizagem, "[...] essa facilidade na administração das situações e dos conteúdos exige um domínio pessoal não apenas dos saberes [...], ou seja, os conceitos, as questões e os paradigmas que estruturam os saberes no seio de uma disciplina". (PERRENOUD, 2000, p. 27)

\section{TIC E O ESPAÇO DE INTERAÇÃO}

As novas abordagens do processo de ensino e aprendizagem direcionam o professor para um trabalho com novos artifícios que visam estimular e motivar os alunos a participarem do processo com intenção de que aprendam com maior facilidade os conteúdos tratados. Sendo assim, há muitos recursos que colaboram nesse processo, como as TICs (Tecnologias da Informação e Comunicação). Diante das novas TICs temos os ambientes virtuais de aprendizagem (AVA) considerados por Goedert et al. (2011), como ferramentas de exercício intelectual que estimula a criação. 
A expressão ambiente virtual de aprendizagem refere-se ao amplo conceito de espaço de aprendizagem, possibilitado pelas tecnologias informáticas. Foram pensados para ajudar os professores no gerenciamento de conteúdos para seus alunos e na administração do curso, possibilitando o acompanhamento constante do progresso dos estudantes. Como ferramenta para EaD, podem ser utilizados para complementar aulas presenciais ou em modelos de EaD totalmente online. (GOEDERT et al., 2011, p. 71)

Em virtude do suporte tecnológico se tem a possibilidade de relacionar o saber com as pessoas e estimular a aprendizagem compartilhada. O suporte tecnológico tem influenciado também na mudança conceitual e de como pensar as aulas. De acordo com Goedert et al., (2011, p. 71):

Essa nova maneira de se relacionar com o saber e com outras pessoas, em virtude das particularidades dos suportes tecnológicos, permitiu a geração de atividades cognitivas diferentes daquelas de situações nas quais esses suportes não são utilizados.

Segundo Silva (2006), um ambiente virtual de aprendizagem é um conjunto de ferramentas e estruturas decisivas para construir da interatividade à aprendizagem em meio a participação de alunos e professores. A saber, todo processo educativo deve basearse pela partilha de informações e comunicação, e nessa dinâmica o AVA, não só vai oferecer ferramentas de interação como também proporcionar a participação em tempo real dos alunos e professor, “[...] podemos dizer, com isso, que as modernas tecnologias, quando aplicadas à educação, provocam mudanças na estruturação do ato de pensar" (GOEDERT et al.,2011, p. 71).

Ainda que se tenha avançado bastante no quesito ensino, e sobretudo, na utilização tecnológica digital dos recursos que temos disponíveis, ainda há muito a se conhecer. Inclusive os alunos, que utilizam tecnologia digital com frequência, no entanto ainda precisam redescobrir este recurso como possível mediador do saber. Como pode-se perceber nas palavras de Faria (2011):

Esta experiência mostrou que apesar dos alunos envolvidos terem amplo contato com as TICs, muito existe para descobrir e explorar, quer a nível da integração na aprendizagem, quer a nível da exploração em função de interesses próprios. A integração em contextos de aprendizagem de ferramentas TIC continua, ainda, a ser uma novidade para muitos alunos, mesmo com 10 anos de frequência 
escolar. Contudo, a sua integração carece de uma apropriada exploração por parte do professor, já que disso depende um sucesso e, como tal uma motivação para replicar a experiência ou introduzir novas, ou um fracasso e, nessas circunstâncias a usual desistência e abandono destas ferramentas. (FARIA, 2011, p. 63)

Afim de não cair na eliminação, ou que essa utilização acabe por acrescentar nas deformações no ensino de ciências, e por outro lado, que alunos e professores passem a utilizar as tecnologias digitais, os ambientes virtuais de aprendizagem disponíveis na rede em prol do ensino e aprendizagem é que faz importante pensar e verificar na prática essa proposta metodológica e assumir assim o risco da redundância 'inovadora'.

\section{A TECNOLOGIA DIGITAL COMO FERRAMENTA PARA ENSINO DE CIÊNCIAS}

Apesar dos consideráveis avanços nas práticas sobre o ensino de ciências, tem-se diariamente percebido as insuficiências refletidas na formação do aluno, causa esta que resulta na falta de criticidade e poder argumentativo para o tratamento das informações. Esse contexto é visto também na ausência das tecnologias nas aulas de Ciências, a falta de dinamização que poderia ser melhor explorada com o auxílio dos AVA, entre outras possibilidades.

Pesquisas de cunho documental tem mostrado que, apesar das vantagens das TICs ao ensino, estas ainda não fazem parte do contexto educacional como se pensa. De acordo com a pesquisa desenvolvida por Scheid e Reis, (2016):

Embora as pesquisas indiquem a significativa contribuição das TIC [...], há uma restrita utilização das mesmas em aulas de Ciências Naturais. Isso pode ter como causa o fato de, muito raramente, nos cursos de formação profissional inicial, ou continuada, os professores serem instrumentalizados para a utilização das TIC com finalidade educativa. Além disso, falta-lhes capacitação e condições/tempo para o planejamento e implementação de projetos interdisciplinares.

Sendo assim, é visto que as práticas relacionadas a levar propostas de cunho interacionistas, dinâmicas e que tenham como veículo os AVA, estão em destaque, pois 
como pode-se perceber na pesquisa acima apresentada, esses recursos, seja pela falta de capacitação docente, tempo e/ou outras condições adversas, não conseguem atingir consideravelmente as salas de aula. Deste modo, as ações que trazem essa perspectiva continuam no centro das discussões atuais.

Um outro fator a ser considerado, quando se discute sobre tecnologia digital e ensino, é o fator 'desigualdades socioeconômicas' que infelizmente atinge uma grande parcela da sociedade e tira o direito do contato com o que está sendo produzido em emergência. Sobretudo, com as exigências atuais, os conhecimentos tecnológicos estão no centro para a profissionalização, entretanto, o suporte tecnológico digital ainda não é realidade para toda uma sociedade que vive conflitos econômicos. Nesse sentido, Souza,et al., (2011, p.213) alertam que "[...] temos que considerar o fato de vivermos em um país de muita desigualdade social, que tem um número elevado da população sem acesso a computadores e muito menos à internet".

Essa é uma questão importante a ser destacada, pois quebra a ideia de que os trabalhos com incentivo à tecnologia em prol da aprendizagem não sejam necessários, visto não ser mais novidade para os alunos e, assim, não chamar sua atenção como era pensado. Essas ideias mostram a falta de informação e compromisso com a formação social do aluno, pois pode tirar a oportunidade de acesso ao tecnológico que muitas vezes acontece apenas quando realizados trabalhos dessa natureza.

Assim, considerando as vantagens já mencionadas até aqui, vale salientar que, quando possível, é importante a utilização dos recursos tecnológicos digitais, sobretudo, no que enfatiza Souza et al.,(2011, p. 218) quando destaca como vantagem “[...] A possibilidade de interagir, através das ferramentas tecnológicas, implica rever todos os papéis dos envolvidos no processo ensino e aprendizagem e como também a metodologia utilizada para a promoção dessa aprendizagem".

\section{O Edmodo}

A plataforma Edmodo vem sendo utilizada em países como os Estados Unidos e Brasil, pode ser gratuita ou paga e está se disseminando como ferramenta utilizada por 
escolas, empresas e salas de aula. A plataforma é esteticamente e funcionalmente muito semelhante ao Facebook.

Segundo Purgly (2013) ela foi criada por NicBorg e Jeff O'Hara como rede social no ano de 2008, com intuito de unir o mundo virtual ao escolar. É de propriedade privada, com sede em San Mateo, California. Seu Slogan é "Uma rede social segura para escolas" (Safe Social Networking for Schools) e pode ser acessada no endereço virtual www.edmodo.com em computadores, celulares com androide, smarthphones e tabletes. Aos que se interessam em utilizar a ferramenta é obrigatório se registrar, e esse é um processo bem simples.

De acordo com Abrantes (2012), a Edmodo é uma plataforma para o gerenciamento da aprendizagem (Learning Management System - LMS), desenvolvido por meio de computação na nuvem. Ela oferece um ambiente virtual seguro para a interação da comunidade escolar. Professores podem dispor de salas de aula on-line, compartilhar conhecimentos e conduzir trabalhos. Tarefas de casa também podem ser feitas, corrigidas e comentadas na própria plataforma, que dispõe, para isso, de softwares integrados. As ferramentas de edição permitem ao professor inserir marcações, comentários e correções nos documentos. Além disso, os arquivos armazenados na biblioteca podem ser acessados a partir de qualquer computador ou smartphone.

É um recurso tecnológico onde, de acordo com Abrantes (2012), os participantes podem compartilhar materiais de estudo, links, apresentações, vídeos, além de acessar tarefas, notas e avisos escolares. A parte gráfica da plataforma oferece experiência de usuário semelhante ao Facebook, é intuitiva e de fácil manejo. O recurso "biblioteca" também está disponível para a conta de estudante, o que pode facilitar a vida do aluno na realização de trabalhos, além de lhe possibilitar a experiência de organizar suas próprias bibliotecas de estudos.

Segundo Purgly (2013) a plataforma já conta com mais de 12 milhões de pessoas e está disposta nos idiomas português, inglês, espanhol, alemão, grego e francês. Foi criado com objetivos de: 
1. Promover o uso responsável das redes sociais e outras ferramentas.

2. Haver maior interação e comunicação entre professores, pais e alunos.

3. Ajudar os educadores a aproveitar o poder das redes sociais para personalizar e dinamizar o ensino.

4. Aliar a tecnologia à educação.

5. Ferramenta de ensino à distância.

6. Contribuir a usar biblioteca online.

7. Partilha de informação mais rapidamente.

8. Incentivar à aprendizagem e ao manuseamento das tecnologias, tornando o utilizador autodidata.

9. Acesso fácil à plataforma através do computador, telemóvel e tablete.

Para garantir a segurança do seu uso existem vários administradores por país e códigos especiais de acesso para escolas e turmas/disciplinas. Um aluno para poder se registar na página Edmodo tem que ter um código que é fornecido para o grupo, ou seja, pelo docente. $\mathrm{O}$ fato de os utilizadores só poderem trocar informação com os membros do grupo onde está inserido, permite que não haja contato com utilizadores indesejados. (PURGLY, 2013)

A plataforma apresenta várias funcionalidades com as quais o professor pode enriquecer sua aula e criar um ambiente interativo em sala e fora dela também. Ainda de acordo com Purgly (2013), ela permite partilhar conteúdos, realizar aplicações educacionais, criar uma biblioteca, conectar-se ao Google Docs, criar e realizar tarefas/trabalhos online, emitir notas, fazer notificações, criar calendários, espaço para troca de ideias, partilha de vídeos, imagens e jogos;

\section{METODOLOGIA}

Este trabalho é um relato de experiência de professores em busca de ferramentas que possibilitem o aprendizado dos alunos em ensino de ciência com uso de TICs em sala de aula. Seus resultados geraram dados importantes para aqueles que buscam formas interativas e digitais na educação. Estes foram analisados qualitativamente segundo a 
Análise de Conteúdo proposta por Bardin (2011, p.15)“a análise do conteúdo é um conjunto de instrumentos de cunho metodológico em constante aperfeiçoamento, que se aplicam a discursos (conteúdos e continentes) extremamente diversificados".

Ocorreu em laboratório de informática no Centro de Ciências e Tecnologia - CCT da Universidade Estadual da Paraíba - UEPB, em decorrência da solicitação de uma atividade na disciplina de Tópicos de Biologia II ( Práticas de Laboratório para o Ensino de Ciências) do Programa de Pós Graduação em Ensino de Ciências e Educação Matemática - PPGECEM, no dia 04 de abril do decorrente ano, uma aula em forma de seminários onde foi exposto, em 60 minutos, uma apresentação metodológica com uso de tecnologia digital, tendo como conteúdo a abordado a célula animal.

A apresentação foi avaliada pela professora da disciplina, Karla Luna e pelos demais colegas de sala, que levaram em consideração a plataforma utilizada como ferramenta para o ensino e as atividades elaboradas com objetivos, conteúdo e dinamicidades voltadas para aplicação no $1^{\circ}$ ano do ensino médio.

A ferramenta online utilizada foi a Edmodo, uma rede social gratuita para professores e alunos partilharem conteúdos e aplicações educacionais. Nela foram propostas duas atividades avaliativas e apresentado, na mesma, materiais de apoio, postagens interativas sobre dúvidas, comentários, links de jogos e ainda uma enquete.

Os professores avaliadores interagiram verificando a plataforma, a página e participando da enquete, julgando o método e conteúdo em ótimo, bom ou monótono e deixando suas opiniões em relação ao uso da aula exposta.

\section{Conteúdo e Atividades}

O conteúdo proposto para a aula foi o de célula animal direcionada ao primeiro ano do ensino médio base em Canto (2009, p. 21) e nas páginas online Guia do Estudante (2012) e Ciências Naturais (2015). Após a exposição de uma aula anterior sobre a célula animal, suas organelas e funções, foi exposto aos alunos a página Edmodo contendo material de apoio sobre a aula, atividades a serem realizadas online, espaços interativos para dúvidas e comentários, como também links de jogos. A apresentação foi realizada em uma hora, mas a 
proposta para uso das atividades em sala para o ensino médio foi de duas aulas de 50 minutos cada.

No primeiro momento de apresentação os alunos do mestrado foram apresentados a nova forma de trabalho, a página virtual da turma do $1^{\circ}$ ano na Edmodo, momento que é proposto para os mais diversos grupos que forem utilizar a ferramenta. 0 professor/apresentador foi descrevendo a forma de utilização da página enquanto direcionava o cadastro para os alunos/professores que iriam avaliar o método em questão. Cada um em um computador ou celular com acesso à internet e com o código disponibilizado pelo professor foi fazendo seu cadastro e já se inteirando do ambiente a ser utilizado.

Ao primeiro contato como membro da página o aluno encontrou uma postagem de boas-vindas com as palavras do professor/apresentador, e o convite a explorar ao máximo esta ferramenta para a troca de informações e aprofundamento de conhecimentos.

Na segunda postagem, com objetivo de chamar a atenção dos alunos para a utilização do ambiente e deixa-lo mais divertido, estavam dispostos três links de jogos interativos da internet sobre o conteúdo visto. Vale ressaltar que a cada postagem os alunos podem deixar comentários sobre a mesma.

$\mathrm{Na}$ terceira postagem o objetivo seria a interação através de perguntas e respostas. Chamada de "Cantinho da Curiosidade" com a proposta de ser um espaço onde os alunos pudessem deixar suas dúvidas e, professores e demais participantes do grupo pudessem responder e discutir sobre as mesmas.

O espaço posterior trazia o material de apoio proposto pelo professor/apresentador, sendo composto por um texto base trabalhado na aula expositiva e mais um link de um blog educativo com uma boa abordagem sobre o conteúdo.

Logo após, encontrava-se a enquete para a opinião dos participantes em relação ao espaço virtual como meio de aprendizado. Neste caso os professores que estavam avaliando a apresentação votaram na enquete, e comentaram sobre a interatividade, atividades e método utilizado. Participaram desta pesquisa 10 professores do PPGECEM, incluindo a professora da disciplina. 
Na sequência estavam contidas duas atividades avaliativas. A primeira intitulada "Era uma vez uma célula animal...", com objetivo de auxiliar no aprendizado sobre a célula animal, as organelas e suas funções. Tinha por proposta que, o aluno usando a criatividade criasse uma estória sobre a célula animal, citando todas as organelas como personagens e ressaltando as funções de cada uma. Esta atividade era avaliativa e para realização em sala. Os textos deveriam ser postos na página, no espaço da postagem desta atividade para a avaliação do professor/apresentador. Esta atividade tinha data de encerramento e quando passa do período de permissão do professor a publicação da mesma fica indisponível para o aluno.

A segunda atividade avaliativa tinha por título "Mapa conceitual da célula animal" com o objetivo de fixação do conteúdo através de mapas. Nela estava contida a imagem inicial de um mapa como exemplo, ao qual o aluno poderia seguir para iniciar seu mapa, e o link da página do Sample Mind Mape, que é uma página online gratuita para criação de mapas de forma livre. Nela os alunos poderiam criar seus logins, fazer seus mapas, salvar como imagem e postar na página Edmodo como comprovação da realização da atividade e avaliação dos professores.

\section{RESULTADOS E DISCUSSÃo}

É interessante perceber que, diante de apenas um assunto, Célula Animal, foi proposto em um único espaço, atividades diferenciadas e muitas informações. A plataforma Edmodo permite uma grande interatividade entre professores e alunos, alunos e alunos, e tem ferramentas disponíveis para a criatividade do professor em relação aos mais diversos conteúdos ao qual ele queira trabalhar.

Para Goulart (2012) estudantes e professores não são os únicos empolgados com as novas ferramentas. Estudiosos também veem com bons olhos as redes sociais educativas. "Esses sistemas permitem uma experiência educacional mais maleável, no sentido de que o professor pode adaptá-la segundo as necessidades da classe. Além disso, ela extrapola os muros da escola. O estudante passa a estar 'conectado' ao saber mesmo fora do período de 
aula", diz Christopher Quintana, especialista em tecnologia da educação da Universidade de Michigan.

A possibilidade de usar os meios eletrônicos de tecnologia como computadores e dispositivos-móveis já é um atrativo a mais para o aprendizado dos alunos, pois a maior parte deles são da era digital. Souza et al., (2011, p. 22) ressaltam que as teorias e práticas associadas à informática na educação vêm repercutindo em nível mundial, justamente porque as ferramentas e mídias digitais oferecem à didática, objetos, espaços e instrumentos capazes de renovar as situações de interação, expressão, criação, comunicação, informação, e colaboração, tornando-a muito diferente daquela tradicionalmente fundamentada na escrita e nos meios impressos.

Meios eletrônicos possibilitam o enriquecimento das aulas com imagens, vídeos, jogos e chamam mais a atenção dos alunos para o aprendizado. Infelizmente o que acontece é que na era digital as escolas ainda não têm estrutura que possibilite o uso constante deste método nas aulas.

De acordo com Souza et al., (2011) o espaço educativo escolar deveria ser constituído de ambientes de troca de saberes e construção de reflexões e práticas transformadoras. Um dos problemas mais debatidos quando se fala em escola e os jovens de hoje é justamente o distanciamento que há entre a cultura escolar e a cultura da juventude. Os conteúdos e conceitos aprendidos em sala de aula muitas vezes não fazem sentido para estes jovens que almejam um futuro que na maioria das vezes não está ligado ou relacionado com o que veem nas salas de aula. Acredita-se que um dos principais motivos deste distanciamento é a falta de espaços comunicativos na escola, que certamente permitiriam uma maior participação dos discentes. (SOUZA et al., 2011, p. 25)

De forma geral, para os alunos/professores que avaliaram a apresentação da plataforma Edmodo como ferramenta metodológica para o uso nas aulas, e as atividades propostas como método de aprendizagem do conteúdo de célula animal, acharam em sua maioria uma ótima opção de utilização em sala das atividades e da ferramenta online.

Deixaram suas opiniões registradas na página Edmodo conforme solicitado em enquete. Dos dez professores participantes da aula, todos comentaram após a apresentação em voz alta sobre a metodologia utilizada. 
Foram comentários positivos e no presente afirmaram que utilizariam este formato de aula em suas salas e ainda seria possível adaptar as atividades propostas para vários conteúdos dentro de suas disciplinas. Quanto ao uso da plataforma Edmodo apenas dois dos presentes já a conheciam e um destes já teria feito uso da mesma em uma escola a qual prestou serviço, porém não sabia que a plataforma poderia ser gratuita e de livre utilização; o segundo não conhecia com detalhes. Contudo, os dois afirmaram a recomendação desta ferramenta como meio de interação moderna entre professores e alunos, capaz de propiciar a aprendizagem.

Dentre os professores participantes, apenas cinco registraram na página suas opiniões votando na enquete proposta e registrando suas palavras como forma de comentário na postagem. A enquete abordava os participantes sobre suas opiniões em relação ao espaço criado para realização das atividades e aprofundamento dos estudos sobre a célula anima. Eles poderiam classificar a utilização do espaço e das atividades como ótimo, bom ou monótono.

Como resultado unânime os professores classificam como ótima a utilização do espaço e das atividades. Deixaram registrados conforme veremos abaixo algumas de suas opiniões como forma de comentário no espaço destinado para este fim.

Prof. 1: "Muito interativo, melhor do que algumas plataformas pagas, e por ser parecido com o facebook prende a atenção do aluno."

Prof. 2: "Excelente opção para trabalhar com os alunos tanto no espaço escolar, quanto em atividades para casa."

Prof. 3: "Muito interessante. Show!"

Em relação as atividades, a utilização da criação de estória e mapa conceitual como atividades avaliativas vem como forma de motivar o aluno a pensar e usar a criatividade através de situações as quais estão trabalhando o conteúdo visto, tudo isto dentro de uma proposta de construção do próprio conhecimento em um ambiente que eles têm grande afinidade, que é o meio virtual.

De acordo com Kubata et al. (2011, p. 2), a postura do professor em sala de aula, bem como suas artimanhas em articular o conteúdo teórico a ser ensinado com atividades mais dinâmicas e uma abordagem moderna são, sem dúvida, pontos de partida para a solução de 
problemas em sala de aula, tanto no sentido disciplinar (comportamento do aluno) quanto no índice de rendimento de conteúdos que serão aproveitados pelo estudante.

Usar o mapa conceitual como parte avaliativa do conteúdo visto é uma ótima opção na promoção da aprendizagem do aluno. Para Maffra (2011, p 16),"o uso de Mapas Conceituais pode estimular e organizar a criação e a comunicação de ideias complexas, propiciando uma aprendizagem significativa e, assim, tornando-se uma estratégia possível para a melhoria do ensino/aprendizagem". E foi pensando nestes pontos que a atividade foi proposta neste conteúdo e com uso das ferramentas online apresentadas poderá ser usada sempre o professor achar conveniente para alcançar os objetivos de aprendizagem proposta.

Ainda de acordo com Maffra (2011), diante da ideia da utilização de mapas conceituais, a aprendizagem parece acontecer através de uma dinâmica de interação entre conhecimentos, gerando a formação de uma rede cognitiva que se reestrutura constantemente durante a aprendizagem significativa e se mantém na memória. Esse método é usado como meio de alcance da aprendizagem significativa defendida por Ausubel (2000), quando ressalta que o produto significativo de um processo psicológico cognitivo ("saber") que envolve a interação entre ideias "logicamente" (culturalmente) significativas, ideias anteriores ("ancoradas") relevantes da estrutura cognitiva particular do aprendiz (ou estrutura dos conhecimentos deste) e o "mecanismo" mental do mesmo para aprender de forma significativa ou para adquirir e reter conhecimentos.

Diante do cenário educacional já vivido até os dias atuais o que se ressalta é o trabalho do professor quanto mediador do conhecimento e a resposta do aluno através do seu aprendizado. $O$ aprendizado do aluno deve ser a principal motivação do professor ao assumir a responsabilidade social de colaborador educacional de cidadãos em formação. E para tanto a busca constante de métodos que facilitem esse processo e obtenha êxito na aprendizagem significativa do indivíduo se faz importante.

Kubataet al. (2011, p. 02) ressalta que a carreira de um professor engloba uma gama de deveres a serem cumpridos, é necessário então, que o mesmo perceba a importância de se preocupar com a qualidade de sua docência. Para que isso aconteça, o professor deve se auto avaliar em todos os dias de seu trabalho, tendo em vista o controle e o conhecimento sobre sua missão, suas características e sua didática. 


\section{CONCLUSÃO}

A partir do que foi proposto e avaliado em sala, pode-se concluir que o uso da tecnologia digital pode enriquecer as aulas por possibilitar muitas formas ilustrativas e uma maior autenticidade de troca de conhecimentos. É uma forma que se mostra mais atrativa para os alunos por ser a maioria nascidos na era digital e terem bom conhecimento do funcionamento de TICs, mesmo em um contexto fora da sala de aula.

O uso da plataforma Edmodo provou ser uma excelente estratégia para professores trabalharem com seus alunos, pois, além de ter uma característica de rede social, possibilita uma maior troca de informações e pode ser acessada em dispositivos móveis de forma descomplicada. Podendo ser recomendado aos professores dos mais diversos níveis educacionais, sendo necessário apenas que exista a possibilidade de acesso a internet por parte de todos os alunos da turma.

Contudo, é necessário que o professor evite exageros, sabendo mediar a utilização das ferramentas propostas, fazendo uma variação de métodos e utilizando não apenas tecnologias digitais em sala, pois existem ainda muitos métodos que podem encantar os alunos além de plataformas online, basta que o professor busque essas formas e aplique de forma interativa aos conteúdos a serem trabalhados.

O uso de atividades que desafiem os alunos a buscarem a informação e utilizarem as mesmas em situações colocados pelos próprios possibilita uma maior chance de aprendizado, uma vez que o aluno será instigado a construir o conhecimento a partir da colocação de situações propostas pelo professor, as quais o próprio aluno pode criar.

\section{REFERÊNCIAS}

ABRANTES, R Conheça o Edmodo, a rede social da educação. 2012. Disponível em: <http://www.colegiojoanadarc.com.br/edmodo>. Acesso em: 08 abr. 2016.

AUSUBEL, D. Aquisição e retenção de conhecimentos: Uma perspectiva cognitiva. Lisboa: Editora Plátano, 2000. $218 \mathrm{p}$.

BARDIN, L. Análise de conteúdo. São Paulo: Edições 70, 2011, 229p. 
Brasil. Secretaria de Educação Fundamental. Parâmetros curriculares nacionais : ciências naturais / Secretaria de Educação Fundamental. - Brasília: MEC/SEF, 1997.

CANTO, E. L.Ciências Naturais: aprendendo com o cotidiano. 3. Ed. São Paulo:Moderna, 2009. p. 21.

CARVALHO, A.M.P.; PEREZ, D. G. Formação de professores de Ciências: tendências e inovações. 8. Ed. São Paulo: Cortez. 2006.

Ciências Naturais: Células do Corpo Humano. Células do Corpo Humano. 2015. Disponível em: <http://www.todamateria.com.br/celulas-do-corpo-humano/>. Acesso em: 19 mar. 2016.

DELIZOICOV, D.; ANGOTTI, J.; PERNAMBUCO, M.; Ensino de Ciências : fundamentos e métodos. -2. ed. - São Paulo: Cortez, 2007.

FARIA, A. N. M. M. C. Utilização do wiki como ferramenta colaborativa deaprendizagem. 143 f. Dissertação (Mestrado em Educação) - Instituto de Educação, Universidade de Lisboa, Lisboa, 2011. Disponível em: <http://repositorio.ul.pt/ handle/10451/6252>. Acesso em: 12 nov. 2015.

FREIRE, P. Pedagogia da Autonomia: saberes necessários à prática educativa. 40. ed. São Paulo: Paz e Terra, 2009.

Guia do Estudante. Biologia: Organização das células eucarióticas. 2012. Disponível em: <http://guiadoestudante.abril.com.br/estudar/biologia/biologia-organizacao-celulas-eucarioticas695236.shtml>. Acesso em: 17 mar. 2016.

GOEDERT, L.; SILVA, M. C. R. F.; MACIEL, V. A. Fundamentos da Educação a Distância. Florianópolis. 2011.

GOULART, N. Parece facebook, mas não é: são as redes educativas. 2012. Revista Veja. Disponível em: <http://veja.abril.com.br/noticia/educacao/parece-o-facebook-mas-nao-e>. Acesso em: 08 abr. 2016.

KUBATA, L.; FRÓES, R. C.; FONTANEZI, R. M. M.; BERNABÉ, F. H L. A postura do professor em sala de aula: atitudes que promovem bons comportamentos e alto rendimento educacional. 2011. Disponível em: <http://periodicos.unifacef.com.br/index.php/rel/article/view/421/404> . Acesso em: 09 abr. 2016.

MAFFRA, S. M. Mapas conceituais como recurso facilitador da aprendizagem significativa: Uma abordagem prática. 2011. 129 f. Dissertação (Mestrado) - Curso de Ensino de Ciencias, Intituto Federal de Educação, Ciência e Tecnologia do Rio de Janeiro, Nilópolis, 2011. Disponível em: <http://www.ifrj.edu.br/webfm_send/3058>. Acesso em: 09 abr. 2016.

MIZUKAMI, M. G. N. Ensino: as abordagens do processo. - São Paulo: EPU, 1986. (Temas básicos de educação e ensino).

PÉREZ, D. G.; MONTORO, I. F.; ALÍS, J. C.; CACHAPUZ, António; PRAIA, João. Para uma imagem não deformada dotrabalho científico. Ciência \& Educação, v.7, n.2, p.125-153, 2001

PERRENOUD, P. Dez novas competências para ensinar. Trad. Patrícia Chittoni Ramos. - Porto Alegre: Armed, 2000.

PURGLY, J. O que é o Edmodo e para que serve. 2013. Disponível em:

<http://hptre.blogspot.com.br/2013/05/o-que-e-o-edmodo-e-para-que-serve.html>. Acesso em: 08 abr. 2016. 
SCHEID, N. M. J.; REIS, P. G. R. As tecnologias da informação e da comunicação e a promoção da discussão e ação sociopolítica em aulas de ciências naturais em contexto português. Ciênc. Educ., Bauru, v. 22, n. 1, p. 129144, 2016.

SILVA, M. Criar e professorar um curso online: relato de experiência. In: SILVA, Marco. (org.). Educação online: teorias, práticas, legislação e formação corporativa. 2. ed. São Paulo: Loyola, 2006.

SOUZA, R. P.; MOITA, F. M. C. S. C.; CARVALHO, A. B. G. (Org.). Tecnologias Digitais na Educação. Campina Grande: Eduepb, 2011. 273 p. Disponível em: <http://static.scielo.org/scielobooks/6pdyn/pdf/sousa9788578791247.pdf>. Acesso em: 09 abr. 2016. 